\title{
The role of computerized tomography in penetrating abdominal trauma
}

\section{O papel da tomografia no trauma abdominal penetrante}

Eduardo lopes Martins Filho'; Melissa Mello Mazepa'; Camila Roginski Guetter, AcCBC-PR'; Silvânia Klug Pimentel, TCBC-PR ${ }^{1,2}$

\author{
A B S T R A C T
}

\begin{abstract}
Objective: to evaluate the role of abdominal computed tomography in the management of penetrating abdominal trauma. Methods: we conducted a historical cohort study of patients treated for penetrating trauma in the anterior abdomen, dorsum or thoracoabdominal transition, that were submitted to a computed tomography carried out on admission. We evaluated the location of the wound and the presence of tomographic findings, and the management of these patients as for nonoperative treatment or laparotomy. We calculated the sensitivity and specificity of computed tomography according to the evolution of the nonoperative treatment or the surgical findings. Results: we selected 61 patients, 31 with trauma to the anterior abdomen and 30 to the dorsum or thoracoabdominal transition. The mortality rate was $6.5 \%(n=4)$, all in the late postoperative period. Eleven patients with trauma to the anterior abdomen were submitted to nonoperative treatment, and 20, to laparotomy. Of the 30 patients with trauma to the dorsum or thoracoabdominal transition, 23 underwent nonoperative treatment and seven, laparotomy. There were three nonoperative treatment failures. In penetrating trauma of the anterior abdomen, the sensitivity of computed tomography was $94.1 \%$ and the negative predictive value was $93.3 \%$. In dorsal or thoracoabdominal transition lesions, the sensitivity was $90 \%$ and the negative predictive value was $95.5 \%$. In both groups, the specificity and the positive predictive value were $100 \%$. Conclusion: the accuracy of computed tomography was adequate to guide the management of stable patients who could be treated conservatively, avoiding mandatory surgery in 34 patients and reducing the morbidity and mortality of non-therapeutic laparotomies.
\end{abstract}

Keywords: Tomography. Abdominal Injuries. Sensitivity and Specificity. Conservative Treatment. Multiple Trauma.

\section{INTRODUCTION}

$\mathrm{T}$ he change in management of penetrating abdominal trauma over time is remarkable. During the late nineteenth and early twentieth centuries, nonoperative treatment of abdominal injuries was the norm, since laparotomies were associated with a prohibitive rate of mortality'. Due to paradigm shifts, with the development of asepsis and anesthetic techniques, patients who suffer from penetrating abdominal trauma have been mandatorily operated ${ }^{2}$. However, it was observed that non-therapeutic laparotomies doubled hospitalization time and significantly increased patients' morbidity ${ }^{3}$. Thus, victims of stabbing injuries were managed conservatively in selected cases ${ }^{4}$, and gunshot wounds, until recently a mandatory indication of laparotomy ${ }^{5}$, also has a shift towards a more judicious treatment ${ }^{6}$.

Bearing in mind that hemodynamic instability, peritonitis, evisceration and impalement are formal indications for surgical exploration ${ }^{7}$, currently nonoperative treatment (NOT) can be performed in selected stable patients who do not present these signs ${ }^{8}$. In order to target patients to this form of treatment, imaging tests, particularly abdominal tomography (CT), are essential ${ }^{9}$. Although the time required for the CT exam is a risk factor for higher mortality in patients with severe abdominal injuries ${ }^{10}$, the careful selection of those who can undergo abdominal CT may be a safe way of directing management in penetrating trauma ${ }^{11}$. Our institution (Hospital do Trabalhador - UFPR) has accumulated considerable experience in the selective management of penetrating abdominal trauma, but

1 - Federal University of Paraná, Curitiba, PR, Brazil. 2 - Hospital do Trabalhador, General Surgery Service, Curitiba, PR, Brazil. 
there are still few studies that evaluate the accuracy of the tomography in this scenario.

Thus, the objective of this study is to evaluate the role of abdominal $\mathrm{CT}$ in victims of penetrating abdominal trauma and to see if the accuracy of tomography in this population is adequate to determine the treatment of the lesions.

\section{METHODS}

We conducted a historical cohort study at the Hospital do Trabalhador, a reference center for trauma care in Curitiba-PR and its metropolitan region. We included patients admitted between January 2014 and June 2015, victims of penetrating trauma to the anterior abdomen, dorsum and thoracoabdominal transition (TAT) who underwent abdominal CT at admission. Thus, we guaranteed the selection of stable patients. Therefore, we analyzed 1837 records of abdominal tomography and cross-checked the data using the records of assaults and homicides of the social work sector of the Hospital do Trabalhador, to identify victims of penetrating abdominal trauma due to stabbing injuries (SI) and gunshot wounds (GSW). We excluded patients without trauma to the anterior abdomen, dorsum or TAT, patients with multiple entry wounds, and patients with missing data on the medical chart. The total number of individuals who underwent abdominal CT for penetrating trauma was 128. Of these, we excluded 37 because they did not present trauma to the anterior abdomen, dorsum or thoracoabdominal transition. Of the 91 remaining patients, we excluded 30 (32.96\%) because they did not present sufficient data in the medical records.

For purposes of anatomical division, we considered the anterior abdomen the region delimited by the xiphoid process and the costal borders superiorly, the axillary lines medium laterally, and the lower symphysis pubis. We defined thoracoabdominal transition as the area between the nipple line and the costal borders. We considered the dorsum as the region between the infrascapular line superiorly, the iliac crests inferiorly, and the median axillary lines laterally ${ }^{12}$.

We evaluated the epidemiological data, the anatomical location of the entry wounds, the abdominal tomography findings, the type of treatment performed (surgical or nonoperative), the main surgical indications, the exploratory laparotomies findings and the treatment outcome. Due to the anatomical differences, we divided the patients into two groups according to the location of the penetrating wound: anterior abdomen group and dorsum/TAT group.

We considered, as positive abdomen CT findings, the abdominal trajectory of the projectile, peritoneal cavity violation, lesions of large vascular structures, solid viscera, diaphragm, urether or bladder, and the presence of free fluid in the abdominal cavity and/or pneumoperitoneum ${ }^{13}$. Those that did not present these findings were negative CT scans.

We calculated sensitivity, specificity, accuracy, positive predictive value and negative predictive value by comparing the $\mathrm{CT}$ findings with the surgical findings in exploratory laparotomies or with the nonoperative treatment (NOT) outcome, depending on the management to which the patient was submitted. Thus, true positives were patients with surgical findings consistent with those of CT or patients who performed NOT for lesions seen on CT and had a favorable evolution. True negatives cases were those with no CT findings who had a favorable evolution of NOT or who underwent exploratory laparotomies without findings, ie, non-therapeutic laparotomy (NTL). False positives happened when CT showed lesions but the surgical findings were not consistent with them, and false negatives, when NOT failed or when laparotomy was clinically indicated and presented findings different from CT ones. We considered NOT failure as hypotension or hematocrit decrease without explanation and evolution to diffuse peritonitis ${ }^{14}$

The study was approved by the Ethics Committee of the Hospital do Trabalhador under the number 45397615.0.0000.5225.

\section{RESULTS}

We included 61 patients in the study, of whom $88.52 \%(n=54)$ were male. Their mean age was $26.8 \pm 9.38$ years. The mechanisms of trauma were gunshot wounds 
in $59.01 \% \quad(n=36)$ and stabbing injuries in $40.99 \%$ $(n=25)$. There were four deaths in this cohort, two due to hemodynamic instability in the postoperative period, and two late ones because of pulmonary and abdominal sepsis. The mortality rate found was, therefore, 6.55\%, all of them being victims of gunshot wounds. We found injuries to the anterior abdomen in $50.82 \%(n=31)$ of the patients, and injuries to the dorsum or TAT in $49.18 \%$ $(n=30)$. We observed positive tomographic findings in $51.61 \%(n=16)$ of patients with trauma to the anterior abdomen and $30 \%(n=9)$ of patients with dorsum/TAT trauma (Table 1).

Table 1. Epidemiological data and trauma mechanism.

\begin{tabular}{lccc}
\hline \multicolumn{1}{c}{ Variable } & $\begin{array}{c}\text { Anterior abdomen } \\
(\mathrm{n}=31)\end{array}$ & $\begin{array}{c}\text { Dorsum/TAT } \\
(\mathrm{n}=30)\end{array}$ & $\begin{array}{c}\text { Total } \\
\mathrm{n}=61\end{array}$ \\
\hline Male $(\%)$ & $28(90.3)$ & $26(86.7)$ & $54(88.5)$ \\
Average age $( \pm \mathrm{SD})$ & $27.8( \pm 9.4)$ & $25.7( \pm 9.2)$ & $26.8( \pm 9.4)$ \\
Mechanism of trauma $(\%)$ & & & \\
$\quad$ Gunshot wound & $20(64.5)$ & $16(53.3)$ & $36(59)$ \\
$\quad$ Stabbing injury & $11(35.5)$ & $14(46.7)$ & $25(41)$
\end{tabular}

SD: standard deviation; TAT: thoracoabdominal transition.

The most common positive findings in patients with trauma to the anterior abdomen were lesions in solid viscera associated with free fluid or pneumoperitoneum (22.58\%), free fluid associated with pneumoperitoneum $(19.35 \%)$, free liquid alone (6.45\%) and isolated lesion of solid viscera (3.23\%). In this group, $48.39 \%$ of the CT scans had negative findings. In the patients with trauma to the dorsum/TAT, 20\% were lesions in solid viscera with free fluid or pneumoperitoneum, 3.33\% pneumoperitoneum, and in $3.33 \%$, isolated solid viscera lesions. In this group, $70 \%$ of the CT scans had negative findings (Table 2).

Table 2. Tomographic findings in penetrating abdominal trauma.

\begin{tabular}{lcc}
\hline \multicolumn{1}{c}{ Variable (\%) } & $\begin{array}{c}\text { Anterior abdomen } \\
(\mathrm{n}=31)\end{array}$ & $\begin{array}{c}\text { Dorsum/TAT } \\
(\mathrm{n}=30)\end{array}$ \\
\hline Free fluid & $2(6.45)$ & 0 \\
Pneumoperitoneum & 0 & $1(3.34)$ \\
Isolated solid viscera injury & $1(3.23)$ & $1(3.33)$ \\
Free liquid and pneumoperitoneum & $6(19.35)$ & 0 \\
Solid viscera injury with free fluid or pneumoperitoneum & $7(22.58)$ & $7(20)$ \\
Negative scan & $15(48.39)$ & $21(70)$ \\
\hline
\end{tabular}

TAT: thoracoabdominal transition.

The CT findings in patients submitted to NOT can be seen in table 3 . 
Table 3. Tomographic findings in patients undergoing NOT.

\begin{tabular}{lcc}
\hline \multicolumn{1}{c}{ Variable (\%) } & $\begin{array}{c}\text { Anterior abdomen } \\
(\mathrm{n}=11)\end{array}$ & $\begin{array}{c}\text { Dorsum/TAT } \\
(\mathrm{n}=23)\end{array}$ \\
\hline Isolated solid viscera injury & $1(9.09 \%)$ & $1(4.34 \%)$ \\
Solid viscera injury and free fluid & 0 & $3(13.04 \%)$ \\
Negative scan & $10(90.91 \%)$ & $19(82.60 \%)$ \\
\hline
\end{tabular}

TAT: thoracoabdominal transition.

Among the $C T$ scans of the patients with trauma to the anterior abdomen, were found 16 true positive exams, 14 true negatives and one false negative due to a grade I lesion of the ileum not seen on the tomography. Among patients with dorsum/TAT trauma, there were nine true positives, 20 true negatives and one false negative, the latter due to the presence of a grade III lesion in jejunum.
For patients with anterior abdominal trauma, CT sensitivity was $94.1 \%$, specificity was $100 \%$, and accuracy was $96.7 \%$. The positive predictive value was $100 \%$ and the negative predictive value was $93.3 \%$. For patients with dorsum/TAT trauma, the CT's sensitivity was $90 \%$, the specificity was $100 \%$, and the accuracy was $96.6 \%$. The positive predictive value was $100 \%$ and the negative predictive value, $95.52 \%$ (Table 4).

Table 4. Accuracy of CT in penetrating abdominal trauma victims.

\begin{tabular}{lcc}
\hline & Anterior abdomen & Dorsum/TAT \\
\hline Sensitivity & $94.10 \%$ & $90 \%$ \\
Specificity & $100 \%$ & $100 \%$ \\
PPV & $100 \%$ & $100 \%$ \\
NPV & $93.30 \%$ & $95.50 \%$ \\
Accuracy & $96.70 \%$ & $96.60 \%$ \\
\hline
\end{tabular}

CT: computed tomography; PPV: positive predictive value; NPV: negative predictive value; TAT: thoracic abdominal transition.

\section{DISCUSSION}

The results presented accompany the current trend towards more individualized treatment in penetrating abdominal trauma, using imaging resources in hemodynamically stable patients and allowing the selection of patients for NOT, which, in addition to reducing costs ${ }^{15}$, is associated with lower morbidity and mortality ${ }^{16}$. Among the available exams, abdominal tomography has become essential ${ }^{9}$, being a rapid examination and providing the surgeon in the emergency room with the security of determining whether surgical treatment is necessary or not. The high positive and negative predictive values found in this study, both in anterior abdomen trauma (PPV $=100 \%$ and NPV $=93.3 \%$ ) and in the dorsum or TAT (PPV $=100 \%$ and $P P V=95.5 \%$ ), are consistent with other works ${ }^{13,17}$ and show that $\mathrm{CT}$ is reliable for the definition of therapeutic management.

It is predicted that trauma in the anterior abdomen presents a higher rate of abdominal viscera lesions and, therefore, will tend to be more surgical. Among the victims of trauma in this topography $(n=31)$ who presented positive findings $(n=16)$, only one was submitted to NOT due to a grade III hepatic lesion, with favorable evolution. The others $(n=15)$ underwent laparotomies, all therapeutic. Among the patients whose 
tomography did not show signs of lesions $(n=15)$, ten were submitted to NOT, with only one failure due to an ileum degree I lesion. The other five patients underwent laparotomies for indications other than the tomographic findings, one being therapeutic for a grade I lesion in ileum, and four were non-therapeutic. Thus, the sensitivity and specificity of tomography to define the management of penetrating trauma in the anterior abdomen proved to be reliable, as in the literature data ${ }^{12,13}$.

In patients with dorsum/TAT trauma, there is usually greater diagnostic doubt ${ }^{18}$, since the back musculature is a much greater obstacle than that of the anterior abdominal wall, so that the abdominal cavity not always get penetrated, thus leading to a smaller incidence of intraabdominal lesions ${ }^{19}$. Considering this diagnostic challenge, we observed that $70 \%(n=21)$ of patients with trauma in this topography did not present tomographic findings. Among them, 19 underwent NOT with favorable evolution and two underwent laparotomies due to failure, one being non-therapeutic because of the presence of a stable retroperitoneal hematoma in zone II, with no need for surgical approach ${ }^{20}$, and one for a jejunum grade III lesion. Among the nine other patients with positive $C T$ findings, four were due to trauma to the liver or kidney, allowing NOT and avoiding non-therapeutic laparotomies. Five patients underwent laparotomy, all being therapeutic. Thus, tomography was also reliable in patients with penetrating trauma to the dorsum or TAT. We emphasize that, in TAT lesions, tomography is essential for the possibility of successfully targeting NOT from liver lesions ${ }^{21,22}$.
The time required to perform a CT scan is associated with a higher mortality rate in patients who require surgical treatment ${ }^{10}$. With this in mind, we observed that our sample had a mortality rate of $6.5 \%$ (four patients). This rate was consistent with the literature data ${ }^{6}$. However, no death occurred during the CT scan, immediately after it or because of NOT failure. All deaths occurred in the late postoperative period due to septic or hemodynamic decompensation. Thus, tomography at admission would hardly be related to the cause of these deaths.

The literature shows an unnecessary rate of laparotomies, ranging from $4.0 \%$ to $14 \%^{14,19}$. Overall, if mandatory laparotomies were performed for penetrating abdominal trauma in this study of 61 patients, 39 (63.9\%) would have undergone nontherapeutic laparotomies. With selective abdominal computed tomography and NOT targeting, this number was reduced to five (8.2\%) patients, avoiding 34 unnecessary laparotomies. The use of abdominal CT in the presence of hemodynamic stability and lack of mandatory indications for laparotomy (peritonitis, evisceration or impalement) clearly reduced morbidity in victims of penetrating abdominal trauma.

Abdominal $\mathrm{CT}$ is an examination that, when indicated in a judicious manner, can be performed safely in patients with penetrating abdominal trauma. This study demonstrates an adequate sensitivity and specificity of the method for detecting traumatic lesions, which allows less aggressive treatments to be performed safely, reducing the morbidity and mortality to which these patients would be exposed to if mandatory laparotomies were performed. 


\begin{abstract}
Objetivo: avaliar o papel da tomografia computadorizada de abdome no manejo do trauma abdominal penetrante. Métodos: estudo de coorte histórico de pacientes tratados por trauma penetrante em abdome anterior, dorso ou transição tóraco-abdominal que realizaram tomografia computadorizada à admissão. Avaliou-se a localização do ferimento e a presença de achados tomográficos, e o manejo desses pacientes quanto ao tratamento não operatório ou laparotomia. A sensibilidade e especificidade da tomografia computadorizada foram calculadas de acordo com a evolução do tratamento não operatório ou com os achados cirúrgicos. Resultados: foram selecionados 61 pacientes, 31 com trauma em abdome anterior e 30 em dorso ou transição tóraco-abdominal. A taxa de mortalidade foi de $6,5 \%(n=4)$, todos no pós-operatório tardio. Onze pacientes com trauma em abdome anterior foram submetidos a tratamento não operatório e 20 à laparotomia. Dos 30 pacientes com trauma em dorso ou transição tóraco-abdominal, 23 realizaram tratamento não operatório e sete foram submetidos à laparotomia. Houve três falhas do tratamento não operatório. Em traumas penetrantes do abdome anterior, a sensibilidade da TC foi de $94,1 \%$ e o valor preditivo negativo, 93,3\%. Em lesões de dorso ou transição tóraco-abdominal, a sensibilidade foi de $90 \%$, e o valor preditivo negativo foi de $95,5 \%$. Em ambos os grupos, a especificidade e o valor preditivo positivo foram de $100 \%$. Conclusão: a acurácia da tomografia computadorizada foi adequada para direcionar o manejo de pacientes estáveis que puderam ser tratados de forma conservadora, evitando cirurgia mandatória em 34 pacientes e reduzindo a morbimortalidade de laparotomias não terapêuticas.
\end{abstract}

Descritores: Tomografia. Traumatismos Abdominais. Sensibilidade e Especificidade. Tratamento Conservador. Traumatismo Múltiplo.

\section{REFERENCES}

1. Loria FL. Historical aspects of penetrating wounds of the abdomen. Surg Gynecol Obstet. 1948;87(6):52149.

2. Moore EE, Moore JB, Van Duzer-Moore S, Thompson JS. Mandatory laparotomy for gunshot wounds penetrating the abdomen. Am J Surg. 1980; 140(6):847-51.

3. Nance FC, Wennar MH, Johnson LW, Ingram JC Jr, Cohn I Jr. Surgical judgment in the management of penetrating wounds of the abdomen: experience with 2212 patients. Ann Surg [Internet]. 1974 May [cited 2016 Oct 12];179(5):639-46. Available from: http:// www.ncbi.nlm.nih.gov/pmc/articles/PMC 1356042/

4. Shaftan GW. Indications for operation in abdominal trauma. The Am J Surg [Internet]. 1960 May [cited 2016 Oct 12];99(5):657-64. Available from: http://linkinghub.elsevier.com/retrieve/ pii/0002961060900106

5. Martin RS, Meredith JW. Management of acute trauma. In: Sabiston D. C. Textbook of Surgery. Durham, North Carolina: Elsevier, 2016. p. 407-48.

6. Navsaria PH, Nicol AJ, Edu S, Gandhi R, Ball CG. Selective nonoperative management in 1106 patients with abdominal gunshot wounds: conclusions on safety, efficacy, and the role of selective CT imaging in a prospective single-center study. Ann Surg. 2015;261(4):760-4.

7. Biffl WL, Leppaniemi A. Management guidelines for penetrating abdominal trauma. World J Surg. 2015;39(6):1373-80.

8. Demetriades D, Velmahos G, Cornwell E 3rd, Berne TV, Cober S, Bhasin PS, et al. Selective nonoperative management of gunshot wounds of the anterior abdomen. Arch Surg. 1997;132(2):178-83 .

9. Jansen JO, Inaba K, Resnick S, Fraga GP, Starling SV, Rizoli SB, et al. Selective non-operative management of abdominal gunshot wounds: survey of practice. Injury. 2013;44(5):639-44.

10. Neal MD, Peitzman $A B$, Forsythe RM, Marshall GT, Rosengart MR, Alarcon $\mathrm{LH}$, et al. Over reliance on computed tomography imaging in patients with severe abdominal injury: is the delay worth the risk? J Trauma. 2011;70(2):278-84.

11. Ginzburg E, Carrillo EH, Kopelman T, McKenney MG, Kirton OC, Shatz DV, et al. The role of computed tomography in selective management of gunshot wounds to the abdomen and flank. J Trauma. 1998;45(6):1005-9.

12. Velmahos GC, Constantinou C, Tillou A, Brown CV, Salim A, Demetriades D. Abdominal computed tomographic scan for patients with gunshot wounds to the abdomen selected for nonoperative 
management. J Trauma. 2005;59(5):1155-60; discussion 1160-1.

13. Ramirez RM, Cureton EL, Ereso AQ, Kwan RO, Dozier KC, Sadjadi J, et al. Single-contrast computed tomography for the triage of patients with penetrating torso trauma. J Trauma. 2009;67(3):583-8.

14. Velmahos $G C$, Demetriades $D$, Toutouzas $K G$, Sarkisyan G, Chan LS, Ishak $R$, et al. Selective nonoperative management in 1,856 patients with abdominal gunshot wounds: should routine laparotomy still be the standard of care? Ann Surg. 2001;234(3):395-402; discussion 402-3.

15. Kim R, Navsaria P, Myer L, Nicol A. Selective nonoperative management of abdominal gunshot wounds: a cost analysis [abstract]. South Afr J Surg. 2009;47;21.

16. Hasaniya N, Demetriades D, Stephens A, Dubrowskiz $\mathrm{R}$, Berne $\mathrm{T}$. Early morbidity and mortality of nontherapeutic operations for penetrating trauma. Am Surg. 1994;60(10):744-7.

17. Dreizin D, Munera F. Multidetector CT for penetrating torso trauma: State of the Art. Radiology. 2015;277(2):338-55.

18. Berg RJ, Karamanos E, Inaba K, Okoye O, Teixeira PG, Demetriades $D$. The persistent diagnostic challenge of thoracoabdominal stab wounds. J Trauma Acute Care Surg. 2014;76(2):418-23.

19. Velmahos GC, Demetriades D, Foianini E, Tatevossian $\mathrm{R}$, Cornwell EE, Asensio J, et al. A selective approach to the management of gunshot wounds to the back.
Am J Surg. 1997;174(3):342-6.

20. Wang F, Wang F. The diagnosis and treatment of traumatic retroperitoneal hematoma. Pak J Med Sci [Internet]. 2013 Apr [cited 2016 Oct 14];29(2):5736. Available from: http://www.ncbi.nlm.nih.gov/ pmc/articles/PMC3809226/

21. Starling SV, Rodrigues BL, Martins MP, da Silva MSA, Drumond DA. Non operative management of gunshot wounds on the right thoracoabdomen. Rev Col Bras Cir. 2012;39(4):286-94.

22. Starling SV, Azevedo $\mathrm{Cl}$, Santana AV, Rodrigues $\mathrm{BL}$, Drumond DA. Isolated liver gunshot injuries: nonoperative management is feasible? Rev Col Bras Cir [Internet]. 2015 Aug [cited 2017 Oct 10];42(4):238-43. Available from: http://www. scielo.br/scielo.php?script=sci_abstract\&pid=S010069912015000500238\&lng=en\&nrm=iso\&tIng=en

Received in: 07/08/2017

Accepted for publication: 02/11/2017

Conflict of interest: none.

Source of funding: none.

\section{Mailing address:}

Eduardo Lopes Martins Filho

E-mail: edulomarfi@hotmail.com /

cguetter@hotmail.com

\section{(cc) BY}

